\title{
Influence of Socio-Cultural Factors on Inclusive Education Among Students \& Teachers in Nairobi Integrated Educational Programme, Kenya
}

\author{
Keitany Julia Jelagat \& Samson Rosana Ondigi \\ Kenyatta University P.o. Box 43844, 00100 Nairobi, Kenya
}

\begin{abstract}
Although inclusive education has been recommended for implementation in Kenyan schools, attitudes are threatening to add another impediment to the development and success. The purpose of the study was to explore the influence of socio-cultural factors on inclusive education among students \& teachers in integrated educational programmes in Kenya. This study adopted cross-sectional survey design. The study employed a descriptive survey design. The study was carried out in two integrated primary schools in Nairobi with a population of 887.Comprising Ministry of Education officials, (MoE), head teachers, class teachers and learners. The sampling procedure employed comprised purposive sampling for all the participants. The sample size consisted of two MoE, two headteachers, seven class teachers, 12 learners with VI and 40 sighted learners. Data was collected through the use of two instruments namely questionnaires and interview guide. For reliability purpose, the researcher used split half techniques of assessing reliability. Data was analyzed using Statistical Package for Social Sciences for Windows. The findings of this study indicated that headteachers and MoE officials view inclusive education as a good idea. However, most parents are not concerned with integration and are marginally involved. Majority of the teachers were of the view that the training they got did not prepare them adequately to meet the educational needs of learners
\end{abstract}

Keywords: Influence, Socio-Cultural Factors, Attitudes, Learners, Integrated Educational Programme.

\section{Introduction}

Research findings from across the globe indicate schools and teachers are struggling to respond to the wide array of students (Willis \& Camp, 2002). Proponents of exclusivity argue that inclusive education is a better education for all participants in schooling and that "differences can be a resource for community development." (Frank, 1999). At the school level, inclusive education seeks to address the learning needs of all with a specific focus on those who are vulnerable to marginalisation and exclusion (UNESCO, 1994). UNESCO promotes inclusive school communities as the most effective way of combating discriminating attitudes creating welcoming community, building an inclusive society and achieving education for all. For long, children with disability have been confined to special schools under the assumption that such institutions offer safe conducive havens for their rehabilitation and academic growth. Contrary to that view, a new rethinking is emerging that special schools serves and stigmatize the disabled and ultimately do not help them integrate and participate in social activities.

There are numerous landmarks conventions proclamations and legal instruments both at international and national level that concern themselves with the importance of inclusive education. PL 94 - 142 (education of all handicapped children act) that was passed in 1975 in USA provided the impetus to bring students from state hospitals and institutions to their home communities and into their home schools. One of the basic premises of this law was that students with disabilities are entitled to a "free and appropriate public education" in the "least restrictive environment" possible. From 1975 until now, much discussion has occurred in both general education and special education arenas about how to implement this federal law. The law has evolved into the current status that is Individual with Disabilities Education Acts (IDEA). The law states that a continuum of placement options be made available to meet the diverse needs of students with special needs.

Salamanca Framework for action. (UNESCO, 1994) maintains among other findings that those with special educational needs must have access to regular schools which should accommodate them within a child centred pedagogy capable of meeting those needs. Regular schools with inclusive orientation are the most effective means of combating discriminating attitudes creating welcoming communities, building an inclusive society and achieving education for all. Moreover, they provide an effective education to the majority of children and improve the efficiency and ultimately the cost - effectiveness of the entire education systems. The right to freedom embraces within itself the right to live with dignity. Education is an intrinsic part of this fundamental right. Unless schools embrace 'difference', they can never deliver one of the basic requirements of education that of transforming an individual into a human being. Inclusive education in schools can certainly offer resistance to the discriminatory trends that are being introduced through revised curriculum and so called 
value-based programme, all working towards bringing in a society what is intolerant and divisive. Historically, schools were set up by local government or by foundations. These institutions often failed to recognise the value of education role in combating discriminatory societal attitudes towards individuals with disability. Accordingly, only the fittest or the brightest students as determined by society were allowed to enter into the education system. Disabled children therefore were excluded. Attitudes research carried out in USA regarding inclusion has provided varied results. Some studies suggest attitudes towards inclusion were strongly influenced by the nature of disabilities. Other studies have indicated that teachers were positive about including only those children whose characteristics were not likely to require extra instructional or management skills on the part of the teacher. An analysis of international research indicates that some change in attitude has occurred over the past 10 years partly as a result of teachers experiencing working with students with special needs and whether they had developed some competencies teaching students with learning difficulties.

\subsection{Social and Cultural Factors Influencing Inclusive Education}

The concept of disability has undergone significant changes the world over. According to Payne and Thomas (1978), the treatment of the disabled has been through five historical eras; the first was the era of extermination. During this era, the Greeks and the Romans killed newly born infants who were found to have physical deformities and severe forms of mental retardation. During the second era, the disabled were ridiculed. The physically handicapped and the mentally retarded were made court clowns and were used to entertain the privileged class. During the middle ages, a social conscience took over. Instead of ridiculing them, the church decided to put the disabled in asylums and accorded them humane and charitable care. The final periods were the eras of education and vocational adequacy. These periods, which stretch to the present, perceive the disabled as capable of benefiting from education, vocational training, self-reliance and other societal norms.

A family's cultural heritage shapes its reaction to/and interpretation of disabilities. Disability being a socially and culturally constructed phenomenon (Linan-Thompson \& Jean, 1997), families from culturally diverse backgrounds may have differing perspectives on the meaning of exceptionality. These alternative views can easily affect the evaluation process, educational planning, life goals and attempts of establishing collaborative relationship (Turnbull \& Turnbull, 2001). A disability should always be considered within its cultural context. Each culture defines what it considers to be deviant as well as normal. Research reveals that families who are culturally diverse seem to suggest that a disability is defined by the child's future. Just as the notion of disability is determined by society, the etiology or cause of a disability is also a reflection of a family's cultural reference. Different cultures perceive the cause of disability differently. Generally speaking, in the United States, they believe that the cause of a disability can be identified and treated scientifically. Families from different cultures may express a belief in fate, spiritual reasons, violation of social taboos, or intergenerational reprisals as possible causes for the child's disability (Hansan, Lynch, \& Wayman, 1990). At the risk of stereotyping, some Hispanic American families may attribute a youngster's disability to "God's will". In Asian American families, a disability, especially if the child is a male, the etiology of the disability may be seen as punishment or retribution for past sins.

The traditional African approach to mainstreaming of children with special needs is influenced by African beliefs, culture and attitudes. Some studies observed that, among the factors contributing to the general apathy and neglect of children with disabilities in emergent African countries are beliefs that regard disability as a curse from the Gods. Disability in Africa is regarded as a continuous tragedy. Many people regard disability as a strain in their social status. Families with children who are disabled tend to hide them. This attitude of shame breeds overprotection since people with disabilities cannot be let out to fend for themselves. Over protection can arise from the shame of others seeing a person with a disability in the family. In some instances, the individual who is disabled is not allowed out in the presence of visitors. The tragic nature of this existence is also believed to engender sadness most of the time. Many associate disability with bad lack and therefore, would not like to visit special schools, or even let their children learn alongside students with disabilities in the same classroom.

The treatment of the persons with disabilities in Africa and other developing countries is not welldocumented. However in Ghana, the most critical barriers to free universal education for students with disabilities are negative attitude and prejudice. Some Ghanians still attribute the causes of disabilities to curses from gods (Agbenyega, Deppler \& Harvey 2005). For example, the people of Northern Ghana belief that newly born child who is disabled is not a human being. It is a fairy, a spirit, a snake and they will find a way of doing away with that child. Others will not kill but hide the child for they would not like anybody to know because they view it as God's punishment for some disobedience. This is consistent with what (Avoke, 2002) notes that negative attitude and persistent low regard for students with disabilities possess serious barrier to social and educational inclusion in Ghana. 
In Zimbabwe, a majority of students with disabilities are from low socio-economic status background (Mpofu, 1999) and their parents or guardians are marginally involved in their schooling. The higher prevalence of disabilities in children from low socio-economic backgrounds in Zimbabwe is due to the parental lack of literacy and inadequate access to preventive medicine or healthcare. Low socio-economic status families might typically lack knowledge about appreciation of community resources that would make the student more successful in school. For example, Mpofu, (2004) reports a case about a father of a child with spastic cerebral palsy who received a wheelchair with the help of an international relief agency. The father used the chair as his personal chair, preventing the child from using it for personal mobility needs and transportation to school.

In Kenya persons with disabilities not only represent a crucial sector of the marginalized population but also face special problems as a result of their disabilities. Most have no access to education, health, employment and rehabilitation. The majority experience hardships as a result of built-in social, cultural and economic prejudices, stigmatization and more often ostracism, abuse and violence. The effect has been that laws intended as instruments of social-engineering and avenues of awareness and intervention in alleviating the plight of the persons with disabilities have not been explicit in addressing cultural and political opportunities that are available in the country. For many children, the presence of impairment leads to a rejection or isolation from experience that is part of normal development. This situation may be exacerbated by faulty family and community attitudes and behaviours during the critical years when children's "worth nothing" is often the prognosis in early childhood.

\subsection{Students' Attitude Towards Inclusion \\ 2.2.1 Students with Disabilities}

Research on the impact of inclusion and mainstreaming of students with disabilities has been mixed. Educators report that inclusion programmes have had positive effects on the academic performance, behaviour and social development of students with mild, moderate and severe disabilities. They learn targeted skills and had higher levels of engaged time than students with disabilities educated in special education programmes. Students in inclusive classrooms had fewer incomplete assignments, improved self-esteem, grades and task behaviour, a greater number of interactions with their peers and a more positive attitude towards school and learning. Research has also proved that access to and time spent in general education programmes appear to enhance students' preparation for adulthood (US Department of Education 2001) to secondary students with disabilities, who spent more time in general education classrooms than their peers who took fewer general education courses. They were more likely to:

- Participate in post-secondary academic programmes;

- Be employed and make higher salaries;

- Live independently;

- Be socially integrated into their communities and

- Be married or engaged.

The personal accounts of students with disabilities with aspect to their experiences in general educational settings also present mixed picture. Some students report that life in the mainstream was characterized by fear, frustration, ridicule and isolation while others saw placement in general education as the defining moment in their lives in terms of friendship, intellectual challenges, self-esteem and success in their careers (Walsh, 1994; Vaughn \& Klingner 1998). Jenkins and Heinen (1989) interviewed over 600 elementary level students concerning their preferences for a pull-out, push in or integrated model for the delivery of specialized instruction and found that the majority of students preferred to receive additional assistance from their general education teachers while the results also indicated that students seemed to prefer the type of programme they were receiving. Older students preferred a pull-out programme more than younger students, in part because they viewed that alternative as the least embarrassing. Padeliadu and Zigmond (1996) found that elementary level student with learning disabilities viewed special education as a positive place where they could receive help. However, they reported that some students were concerned that they were missing academic instruction or recreational activities while they were receiving special education services. Guterman (1995) studied the effects of special education placements from the perspectives of nine high school students receiving special education services in a self-contained classroom. In terms of social development, she found that students worried that they would lose their friends, feel stigmatized and personally deficient. Academically, students viewed their special education placement as being low level, irrelevant and repetitive, and not helping them learn much. However, because they believed that it was not reasonable for their general education to accommodate their learning needs, and that such accommodations would lead to increased academic stigma, they believed that their placement in a special education class was appropriate. Reid and Button (1995) analysed students with disabilities narratives of their personal experiences with education in segregated schools and found that these students experienced feelings of isolation, victimization, betrayal, oppression, being misunderstood and unappreciated. Albinger (1995) interviewed students with disabilities and found that these students viewed having to leave the general classroom to receive specialized services as a stigmatizing experience. As a result, they fabricated stories to justify to their friends why they were leaving class.

DOI: $10.9790 / 7388-0701024955 \quad$ www.iosrjournals.org $\quad 51 \mid$ Page




\subsubsection{Students without Disabilities}

Educators and parents are concerned that the academic and behavioural needs of students in inclusive programmes will require excessive teacher attention and therefore, jeopardize the education and safety of students who are not disabled. Hehir (1995) notes that the programmes that give special education teachers and teacher aids the opportunity to work in the general education classrooms with both students with and without disabilities resulted in an "incidental benefit" to students who are not disabled. These incidental benefits include the increased use of individualized instruction, the availability of another staff member to assist in promoting improved classroom discipline, and the opportunity to learn about human diversity and the delivery of instructional adaptations and other relevant interventions for students who are experiencing difficulties in school but have not yet been identified as needing special education.

California Research Institute (1992) suggests that:

a) The achievement test performance of students who are not disabled was equal to or better than that of general education students not educated in inclusion programmes.

b) General education students developed more positive attitudes towards and meaningful friendships with their classmates with disabilities.

c) General education students did not pick up inappropriate behaviours from their peers with disabilities.

d) The self-concept, self-skills, and problem-solving skills of all students in inclusion programmes improved and General education students developed personal moral and ethical principles reflecting a greater sensitivity to the needs of others.

e) General education students developed personal moral and ethical principles reflecting a greater sensitivity to the needs of others.

Capper and Pickett (1994) found that students at the traditional school were more prone to stereotyping and held more negative characterizations of peers with disabilities and diversity. In contrast, the students at the inclusive education school exhibited reduced fear of human differences and greater understanding and tolerance of others, including their peers with disabilities. York, Vandercook, Macdonald, Helse-Neff and Caughey (1992) surveyed middle school students without disabilities concerning their reactions to being in inclusive classes. The results indicated that these students:

a) Overwhelmingly believed that inclusion was a good idea;

b) Reported that the inclusion programme had a positive impact on students with disabilities, particularly in terms of social and interpersonal skills, and

c) Developed more realistic and positive perspectives concerning their classmates without disabilities.

Most research studies tend to consistently underscore positive peer perspectives Fisher, (1999). In one of these studies, over 250 high school students had an opportunity to share their perspectives about inclusion (Fisher 1999). Key findings included the following:

a) Their rationale for inclusion was to commit to human rights, to help students with disabilities improve social skills, and provide preparation to the "real world", to assist peers in learning more tolerance, and to enable all students to benefit from educators' instructional adaptations.

b) They expressed concerns related to students with disabilities being teased, not being given the same consequences for inappropriate behaviour as their classmates without

c) Students with disabilities are being treated by some adults in the school in an attitudinally negative way.

d) They suggested enhancing the positive attitudes of educators and ensuring that students with disabilities are more actively involved in school events.

\subsection{Teachers Attitudes Towards Inclusive Education; A Kenyan View}

The successful implementation of inclusive practices relies heavily on general and special education teachers' attitude towards inclusion. Traditionally, the general education teachers have been pessimistic about the increased mainstreaming of children with disabilities in their class. It is known that teacher attitude can affect the learning atmosphere and can influence whether or not students with disabilities receive equitable educational opportunities. The teachers' attitude will trickle down to the learners who will be affected either positively or negatively. Otherwise being the pillars of inclusive education, there is need to investigate their attitudes.

In Kenya, teachers' attitudes towards inclusive education are varied. Teachers feel that they are not prepared to handle learners with diverse disabilities in regular classrooms. They feel that they are not trained and therefore, ill-prepared and unequipped with the knowledge to handle them. There exist negative attitudes on part of the teachers and other stakeholders on inclusive education. Schools view the learners with special needs in education as ones who have the problem. Further, the communities and parents are ill prepared to support the children with special needs in education adequately (Kochung, 2003). Other factors which may negatively influence the implementation of inclusive education in Kenya include: 
a) An acute shortage of teaching aids, equipment and human resources to support inclusive education in the regular schools.

b) The system of examination, which currently emphasises the use of the mean score type of grading in schools. This practice is not in favour of inclusive education as many headteachers decline to admit learners with SNE in their schools feeling that their presence will negatively affect the schools' mean in national examination grading.

c) Lack of enough trained teachers in SNE that would provide support to learners with special needs in the regular schools. Most teachers in regular schools have not been trained to work with learners with diverse needs.

d) Curriculum used in ordinary regular schools is rigid and overloaded and does not take care of the individual needs of learners with SNE.

e) The teacher-learner ratio has gone up following the provision of free primary education. Inclusive education would make extra demands on teachers who are already finding it difficult to cope with their teaching loads considering the fact that schools are understaffed.

f) Lack of barrier free facilities; schools are inaccessible to learners with special needs in terms of desks, toilets, doors, curriculum and paths (Kochung, 2003).

\section{Objective of the Study}

To identify the influence of socio-cultural factors on inclusive education among students \& teachers in integrated educational programmes

\section{Research Question}

What is the influence of socio-cultural factors on inclusive education among students $\&$ teachers in integrated educational programmes?

\section{Methodology}

This study adopted a descriptive research design. The target population was 887 . Which comprised of Ministry of Education officials, (MoE), head teachers, class teachers and learners. The sampling procedure employed in the study was purposive sampling for all the participants. The sample size consisted of two MoE officials, two headteachers, seven class teachers, 12 learners with VI and 40 sighted learners. Two instruments were used in the study namely questionnaires and an interview guide.

\section{Findings And Discussions}

The objective of this study aimed at establishing the socio-cultural factors influencing inclusive education. Some of the statements were given to respondents who in turn supposed to indicate whether they Strongly Agreed, Agreed, Disagreed or Strongly Disagreed. The findings in table 1 indicate that all the teachers sampled were of the view that inclusive education is a good idea, and (6) 85.7\% agreed that learners without VI have positive attitudes towards friendship with their classmates who are VI. Another (6) $85.7 \%$ agreed to the statement that most of the learners with VI show some withdrawal symptoms in class.

Table 1: Social-cultural factors as per teachers' views

\begin{tabular}{|c|c|c|c|c|}
\hline Statements & $\begin{array}{ll}1 . & S A \\
(\%) & \end{array}$ & $\begin{array}{ll}2 . & A \\
(\%) & \end{array}$ & $\begin{array}{ll}3 . & D \\
(\%) & \end{array}$ & $S D(\%)$ \\
\hline Inclusive education is a good idea & 85.7 & 14.3 & 0 & 0 \\
\hline $\begin{array}{l}\text { Learners without visual impairment have positive attitudes } \\
\text { towards friendship with their visually impaired classmates. }\end{array}$ & 42.9 & 42.9 & 0 & 14.3 \\
\hline I enjoy teaching learners with visual impairment in my class. & 57.2 & 14.3 & 14.3 & 14.3 \\
\hline $\begin{array}{l}\text { Some parents are not happy that their sighted children are } \\
\text { learning in the same class with visually impaired children. }\end{array}$ & 14.3 & 14.3 & 57.1 & 14.3 \\
\hline $\begin{array}{l}\text { Most parents are not concerned with the integrated programme } \\
\text { in the school. }\end{array}$ & 28.6 & 14.3 & 42.9 & 14.3 \\
\hline $\begin{array}{l}\text { In my opinion, visually impaired learners would benefit more } \\
\text { from residential schools for the blind. }\end{array}$ & 14.3 & 28.6 & 14.3 & 42.9 \\
\hline
\end{tabular}


This was noted by California Research Institute (1992) that general education students developed more positive friendships with their classmates with disabilities. Research by Walsh (1994), Vaughn \& Klingrer (1998) indicates present mixed picture. Five $71.5 \%$ of them indicated that they treat all learners equally, indicating that the teachers are positive about schooling of the learners with VI, (3) $42.9 \%$ were for the opinion that most parents are not concerned with this arrangement. The findings are in agreement with Mpofu (1999) who observed that parents or guardians were marginally involved in the schooling of their children with disabilities. This shows that as per the teachers' views, most parents are concerned about inclusive education. Table 2 shows the results.

Table 2: Socio-cultural factors as per views from pupils without VI

\begin{tabular}{|c|c|c|c|c|}
\hline Statements & $\begin{array}{ll}\text { I. } & S A \\
\text { II. } & (\%) \\
\end{array}$ & $\begin{array}{ll}\text { III. } & A \\
I V . & (\%)\end{array}$ & $\begin{array}{ll}V . & D \\
V I . & (\%)\end{array}$ & $\begin{array}{ll}\text { VII. } & S D \\
\text { VIII. } & (\%)\end{array}$ \\
\hline I have friends who are visually impaired. & 87.5 & 7.5 & 0 & 5.0 \\
\hline I play with learners with visual impairment & 72.5 & 20.0 & 2.5 & 5.0 \\
\hline Learners with visual impairment disturb us in class. & 5.0 & 10.0 & 7.5 & 77.5 \\
\hline I hate learners with visual impairment. & 0 & 0 & 5.0 & 95.0 \\
\hline $\begin{array}{l}\text { My parents allow me to play with children with disabilities at } \\
\text { home. }\end{array}$ & 80.0 & 10.0 & 2.5 & 7.5 \\
\hline I like doing group activities with learners with visual impairment. & 77.5 & 17.5 & 0 & 5.0 \\
\hline I enjoy learning with learners with visual impairment in my class. & 85.0 & 12.5 & 0 & 2.5 \\
\hline Learners with visual impairment disturb teachers in class. & 5.0 & 12.5 & 10.0 & 72.5 \\
\hline Learners with visual impairment should have their own school. & 2.5 & 10.0 & 5.0 & 82.5 \\
\hline $\begin{array}{l}\text { Learners with visual impairment throw tantrums over small } \\
\text { issues in class and even during play. }\end{array}$ & 2.5 & 2.5 & 37.5 & 57.5 \\
\hline
\end{tabular}

Pupils without visual impairment were also given statements related to the socio-cultural factors. This information is summarized in table 2 above. All pupils without VI did not agree with the statement that they hate learners with VI. Majority, (39) $97.5 \%$ agreed that they enjoy learning with learners with VI in class, (38) 95\% of the pupils agreed that they had friends who were VI, another (37) $92.5 \%$ indicated that they play with them. Others (36) $90 \%$ agreed that their parents allow them to play with children with disabilities at home while a further (34) $85 \%$ indicate that they like doing group activities with learners with VI. A further (33) $82.5 \%$ of the pupils disagreed to the statement that learners with VI disturb teachers in class. The above indicate that pupils without VI have positive attitude towards inclusive education. These findings are in agreement with York et al., (1992) who indicated that students believed that inclusion was a good idea. Table 3 below gives the findings.

Table 3: Socio-cultural factors as per views from pupils with VI

\begin{tabular}{|c|c|c|c|c|}
\hline Statements & $\begin{array}{ll}4 . & S A \\
5 . & (\%)\end{array}$ & $\begin{array}{ll}6 . & A \\
7 . & (\%)\end{array}$ & $\begin{array}{ll}8 . & D \\
9 . & (\%)\end{array}$ & $\begin{array}{ll}10 . & S D \\
11 . & (\%)\end{array}$ \\
\hline Pupils in my class are friendly. & 100.0 & 0 & 0 & 0 \\
\hline I hate students in my class. & 50.0 & 0 & 33.3 & 16.7 \\
\hline Students in my class are supportive. & 50.0 & 50.0 & 0 & 0 \\
\hline I prefer working alone in class. & 91.7 & 8.3 & 0 & 0 \\
\hline $\begin{array}{l}\text { Students in my class do not like supporting VI } \\
\text { learners. }\end{array}$ & 50.0 & 25.0 & 16.7 & 8.3 \\
\hline $\begin{array}{l}\text { My parents allow me to play with my friends who } \\
\text { are sighted. }\end{array}$ & 100 & 0 & 0 & 0 \\
\hline $\begin{array}{l}\text { My neighbours do not allow their children to play } \\
\text { with me. }\end{array}$ & 25.0 & 16.7 & & 58.3 \\
\hline I hate my neighbours at home. & 16.7 & 0 & 0 & 83.3 \\
\hline $\begin{array}{l}\text { My parents do not allow me to eat in front of } \\
\text { visitors at home. }\end{array}$ & 16.7 & 0 & 0 & 83.3 \\
\hline My parents are happy with my school. & 100.0 & 0 & 0 & 0 \\
\hline My parents help me with homework at home. & 83.3 & 0 & 0 & 16.7 \\
\hline My parents ensure that I come to school early. & 100.0 & 0 & 0 & 0 \\
\hline
\end{tabular}

Pupils with visual impairment were also given statements related to the social-cultural factors. This information is summarized in Table 3. All pupils with visual impairment agreed to the following statements; that their peers were friendly, their parents are happy about their school and that their parents allow them to play with their peers who are sighted. Also, all pupils with visual impairment agreed that they prefer working alone in class while a further (9) 75\% indicated that pupils in class do not like supporting learners with VI. This shows that although learners with VI agreed that pupils in class are friendly, they did not support them in class which makes them prefer working alone. These findings are in agreement with Walsh (1994); Vaughn and Klingner (1998) who indicated that the personal accountants of students with disabilities with aspect to their experiences 
in general educational settings present mixed picture. Some reported that life in the mainstream was characterized by fear, frustration, ridicule and isolation while others saw placement in general education as the defining moments in their lives in terms of friendship, intellectual challenges, self-esteem and success in careers.

\section{Conclusion}

The study concluded that learners with VI agreed that pupils in class are friendly but were not supporting them fully in class which made them prefer working alone. The learners with VI preferred female teachers to male teachers.

\section{Recommendations}

Based on the findings of the study, it was recommended that sensitization should be done in schools and the community to eliminate negative attitudes towards inclusion. The Ministry of Education ensure that more teachers are trained in special needs education (SNE) more specifically the headteachers.

\section{References}

[1]. Willis, D. \& Camp, R..(2002,13th November) Key competencies required for teachers to work in and foster inclusive school communities. paper presented at the teachers education for inclusion, talk Cowan University ,Porthsmouth.

[2]. Frank,C.(1999).Ethnographic eyes; A teachers guide classroom observation Porthsmouth, N. H. Heinemann. UNESCO (1994). The Salamanca statement and Frame for Action on Special needs Education Salamanca Spain; World conference on Special Needs Education; Access and Quality.

[3]. Payne, J.S. \& Thomas, C. (1978). The mentally retarded. Columbus, OH: Menrill.

[4]. Linan - Thompson, S. \& Jean, R. (1997). Completing the parent participation puzzle: Accepting diversity. Teaching Exceptional Children 30 (2), $46-50$.

[5]. Turnball, A; \& Turnball, H. (2001). Families, professionals and acceptionality; A special partnership (4th ed) Upper Suddle River, NJ; Prentice-Hall.

[6]. Hanson, M., Lynch, E; \& Wayman, K. (1990). Honouring the cultural diversity of families when gathering data. Topics in Early Childhood Special Education, 10 (1) 112 - 131

[7]. Agbenyega, J.S. \& Deppler, J. Harvey, D. (2005). Attitudes towards inclusive education. In Africa Scale (ATIA): An instrument to measure teachers' attitudes towards inclusive education for students with disabilities. Journal of Research and Development in Education, 5 (1-5).Eggebeen, D.J., Lichter, D.T., (1991). Race Family Structure and Changing Poverty Among American Children American Sociological Review 56, 801-817

[8]. Avoke, M. (2002). Models of disability in the labelling and attitudinal discourse in Ghana. Disability and Society, 17(7), $769-777$.

[9]. Mpofu, E. (1999). Social acceptance of early adolescence with physical disabilities. Unpublished doctoral dissertation University of Wisconsin-Madison, Madison, WI.Giddens. A., (2005). Introduction To Sociology, 5th Edition. U.S.A.: W.W. Norton AndCompany.

[10]. United States Department of Education (2001). Twenty - third Annual Report of Congress on the Implementation of the Individuals with Disabilities Education Act. Washington DC: Office of Special Education Programs.

[11]. Walsh, R. (1994). Making the journey to communication with assistive technology. Exceptional Parents, 24(11), 37-

[12]. Vaughn, S. \& Klingner, J. (1998). Students perceptions of inclusion and resource room settings. The Journal of Special Education. 32(2), 79-88

[13]. Jenkins, J.R.,\& Heinen, A. (1989). Students' preferences for service delivery: Pull-out, in-class, or integrated models. Exceptional children, 55, 516- 523

[14]. Padeliadu, S., \& Zigmond, N. (1996). Perspectives of students with learning Disabilities about special education placement. Learning Disabilities Research and Practice, 11(1),15-23.

[15]. Guterman,B.R. (1995). The validity of learning disabilities services: The consumer's views. Exceptional Children 62(2), $111-124$.

[16]. Reid, D.K. \& Button,L.J., (1995). Anna's story; Narratives of personal experience about being labelled learning disabled. Journal of learning disabilities, 28(10), 602-614.

[17]. Albinger, P. (1995). Stories from the resource room. Piano lessons, imaginary illness and broken down cars. Journal of Learning Disabilities, 28(10), 615-621.

[18]. Hehir,T. (1995). Improving the individuals with disabilities education act. IDEA reauthorization (draft). Washington DC:Office of Special Education and Rehabilitation services.

[19]. California Research Institute (1992). Educational practices in integrated settings associated with positive student outcomes. San Francisco: San Francisco State University.

[20]. Capper, C.A., \& Pickett,R.S., (1994). The relationship between school structure and culture and students views of diversity and inclusive education. The Special Education Leadership Review, 2(1), 102-122.

[21]. Fisher, D., [1999]. According to their peers; Inclusion as high school students see in mental retardation. 17(6), 458-467. (1997). Inclusive education in Australia. Special Education Perspectives 6(1), 21-26..

[22]. Kochung, E. (Nov, 2003). Report of the Task Force on Special Needs in Education. Government Printer 